[in: Linguistics in the Netherlands 2019. Amsterdam / Philadelphia: Benjamins]

\title{
Fifty years of morphological theory in the Netherlands
}

\author{
Geert Booij (University of Leiden)
}

In1965, I became a student of Dutch and general linguistics at the Rijksuniversiteit Groningen. At that time, an important change took place in the Netherlands as to the way in which languages are studied: not only as unique systems, but also as specimens of natural language in general. This meant that linguistic theory acquired a central position in the framing of research questions. The rise of generative grammar played an important role in this change of perspective within Dutch linguistics. In 1966, my Dutch linguistics professor Albert Sassen (1921-1999), a philologist and morphologist, introduced generative grammar into the Dutch study program in Groningen by discussing the first Dutch dissertation written in the framework of generative grammar, Kraak (1966), in his syntax course for $2^{\text {nd }}$ year students (I was one of them). A year later, professor Henk Schultink (1924-2017) of Utrecht University, who wrote a famous dissertation on the morphology of Dutch (Schultink 1962) and acted as co-supervisor of my dissertation (Booij 1977), published a long introductory article on generative grammar in De Nieuwe Taalgids, a traditional journal for students of Dutch (Schultink 1967). This illustrates how an older generation of linguists took these new developments very seriously. Thus, a new generation of linguists was raised with a strong orientation towards American and generative linguistics.

Although the rise of generative grammar gave an enormous boost to grammatical research in the Netherlands, it took some time before morphological issues received proper attention, with at least one exception, Botha (1968), a dissertation written in the framework of generative grammar under supervision of Schultink, on compounding in Afrikaans and the nature of the lexicon. The first dissertation on morphology at MIT, written by Mark Aronoff in 1974, was published as Aronoff (1976). In 1975, Frans Zwarts invited Aronoff to give a lecture on generative morphology in Groningen. This event turned out to be the first Morfologiedag, a conference for Dutch linguists working on morphology. Jaap van Marle and I organized a second edition of this event at the University of Amsterdam in 1976. Since then, the Morfologiedag has been organized on an annual and sometimes bi-annual basis at various universities in the Netherlands and Belgium, and more recently it became a two-day conference, hence Morfologiedagen or Morphology Days. In addition, the TIN-dag (Linguistics in the Netherlands) became an important forum for morphological papers and discussions.

The intellectual history behind Aronoff's influential monograph is described by himself as follows:

"The title of the published version of my dissertation, Word Formation in Generative Grammar (Aronoff 1976) was suggested by S. Jay Keyser, the editor of the series of which this would be the inaugural monograph. It only served to strengthen the impression that I had integrated the study of word-formation into generative grammar. [....]

Nothing could be further from the truth. The title of the monograph was deeply deceptive and in agreeing to it I was also deceiving myself. Word formation rules, as conceived of and discussed in that monograph, are incompatible with generative grammar or 
with any grammar-based linguistic framework, because, like the tradition they encode, these rules cross the synchronic-diachronic boundary that is central to all post-Saussurean structural linguistics. I have only recently come to appreciate this fact. I certainly believed at the time that I was doing generative grammar, as have most of the book's readers since. What is true is that I was a member of a social community self-organized around generative grammar. I did my work on word-formation within that community and it was accepted as legitimate almost entirely on those social grounds." (Aronoff 2018: 11)

In the Netherlands, as at MIT, syntax and phonology were the main topics in the sixties and the seventies of the $20^{\text {th }}$ century, and there was hardly any attention for morphology, a situation aptly described as morphology being "the Poland of linguistics" (Spencer and Zwicky 1998:1), divided between syntax and phonology, a situation that is continued in the model of Distributed Morphology (DM) that is nowadays popular among some generative syntacticians. It was Aronoff's monograph that stimulated Dutch linguists to pursue morphological research as a separate subdiscipline within the generative framework. My dissertation (Booij 1977) is a specimen of this influence. It has also been written because, when I was working on the phonology of Dutch, I discovered that in the derivational approach to phonology of Chomsky and Halle (1968), the morphological structure of words was mainly a vehicle for getting phonological derivations right, and not based on independently motivated morphological insights, thus leading to doubtful morphological analyses of words. As may be expected from a generative framework, the theoretical focus was on morphological creativity, on the kind of knowledge that enables language users to form new words and word-forms by means of rules. This focus on the generative aspect of inflection and word formation has been continued in the theoretical framework of DM. The adherents of DM consider syntax as the sole generative engine of the grammar, and aim at accounting for the generation and structure of complex words by means of syntactic structures (see Creemers et al. (2018) for a DM analysis of Dutch word formation).

The Dutch tradition of morphology before the rise of generative grammar in the 1960s had a different focus, even though it also wanted to account for the word-forming creativity of the language user. As Schultink (1962) pointed out, the discovery of morphological patterns is based on systematic form-meaning correspondences between sets of existing words. This means that paradigmatic relationships between words in the lexicon form the bases for discovering a creative morphological engine. Some of these form-meaning correspondences can be extended to new cases, which means that the relevant patterns are productive. However, there are also unproductive and marginally productive patterns.

Since the 1980s, quite a number of Dutch morphologists stressed the importance of paradigmatic relations and the notion 'productivity', as can be seen in the work of Baayen (my first Ph.D. student at the Vrije Universiteit), Hüning, Van Marle and Van Santen, among others. Concise information on their work can be found in the textbook Booij \& Van Santen (2017) and in Booij (2019). Their approach to morphology can be characterized as word-based, since words form the starting point of morphological analysis. Morphology is not the syntax of morphemes, as was the dominant view in the early days of generative morphology, and morphemes play a secondary role only in accounting for morphological regularities.

Aronoff (1976), who also defended word-based morphology, formulated morphological rules as rewrite rules:

"It bore close resemblance in form to the rewrite rules that were standard in generative grammar. A W[ord] F[ormation] R[ule] took a word from one of the three major lexical categories (Noun, Verb, or Adjective) and mapped it onto a lexical category (the same or another), usually adding an affix, and making another word. The rule of un-prefixation, for 
example, could be written as $[\mathrm{X}]_{\mathrm{A}} \rightarrow\left[\mathrm{un}-[\mathrm{X}]_{\mathrm{A}}\right]_{\mathrm{A}}$ or it could be written simply as the output [un- $\left.[\mathrm{X}]_{\mathrm{A}}\right]_{\mathrm{A}} . "$ (Aronoff 2018: 11)

Indeed, as stated in the last sentence of this quote, word formation processes can be characterized in terms of output schemas, which means that the rule format is not relevant. Similarly, in Oniga's description of the morphological system of Latin (Oniga 2014) that is meant explicitly as a generative description, the author speaks about rules, but uses only output schemas to formalize morphological generalizations.

Morphological schemas have two functions: they function as redundancy statements with respect to existing complex words, and they specify how new words can be formed. The first function (redundancy) has already been argued for in one of the first articles on morphology in a generative framework, Jackendoff (1975). The redundancy function means that morphological schemas have first and foremost a motivating function: they reduce the degree of arbitrariness in the properties of existing complex words. This is also the perspective taken in Construction Morphology (Booij 2010, 2017), and its sister-theory Relation Morphology (Jackendoff \& Audring to appear). This links morphology directly to the study of the lexicon, and its internal structure, the view alluded to by Aronoff at the end of the first quotation given above. The second function of morphological schemas is the creative, generative one: they account for the capacity of language users to coin and understand new complex words.

Morphological research in the Netherlands profited from the presence of the Max Planck Institute for Psycholinguistics (MPI) in Nijmegen, because the study of word processing, an important topic of the research program of MPI, requires understanding of the morphological structure of complex words. The results of experimental research such as lexical decision tasks gave much insight into the nature of the mental lexicon. For instance, it became clear that even completely regular complex words are often stored in lexical memory. Whereas the DM approach to morphology does not care about psychological reality, and aims at a redundancy-free lexicon, theories such as Construction Morphology and Relational Morphology do care about 'graceful integration', the requirement that theories of the architecture of grammar should be in line with findings from related fields such as psycholinguistics and historical linguistics. Therefore, the latter two theories assume a rich lexicon, full of redundant, predictable information.

Another development that changed the way in which morphological research is executed is the continuous increase of available tools: annotated corpora, electronic dictionaries, search programs, and the internet as database. This has made it possible to investigate phenomena such as the degree of productivity of morphological processes in a far more sophisticated way than in the pre-digital era when my dissertation was written. The same applies to historical morphology.

The series Linguistics in the Netherlands reflects the ambition to make Dutch linguistic research visible for the world at large. Similarly, Dutch morphological research acquired a high visibility at the international level through the book series Yearbook of Morphology (1988-2005) edited by Jaap van Marle and myself. As of 2006, this book series is being continued as a full-fledged journal, Morphology.

In conclusion, morphology is a lively subdiscipline of Dutch linguistics with many chances to continue its role in linguistic theory and debates on the architecture of grammar. 


\section{References}

Aronoff, Mark (1976). Word formation in generative grammar. Cambridge Mass.: MIT Press.

Aronoff, Mark (2018). Morphology and words: A memoir. In Olivier Bonami, Gilles Boyé, Georgette Dal, Hélène Giraudo and Fiammetta Namer (eds.), The lexeme in descriptive and theoretical morphology. Berlin: Language Science Press, 3-18.

Booij, Geert (1977). Dutch morphology. A study of word formation in generative grammar. Lisse/

Dordrecht: Peter de Ridder Press / Foris Publications.

Booij, Geert (2010). Construction morphology. Oxford: Oxford University Press.

Booij, Geert (2017). Inheritance and motivation in Construction Morphology. In Nikolas Gisborne and Andrew Hippisley (eds.), Defaults in morphological theory. Oxford: Oxford University Press, 18-39.

Booij, Geert (2019). The morphology of Dutch. $2^{\text {nd }}$ edition. Oxford: Oxford University Press [2002 ${ }^{1}$.

Booij, Geert and Ariane van Santen (2017). Morfologie, de woordstructuur van het Nederlands. $3^{\text {rd }}$ edition Amsterdam: Amsterdam University Press. $\left[1995^{1}, 1998^{2}\right]$

Botha, Rudolf. P. (1968). The function of the lexicon in transformational generative grammar. The Hague-Paris: Mouton.

Chomsky, Noam \& Morris Halle (1968). The sound pattern of English. New York: Harper and Row.

Creemers, Ava, Jan Don, and Paula Fenger (2018). Some affixes are roots, others are heads. Natural Language and Linguistic Theory 36, 45-84.

Jackendoff, Ray (1975). Semantic and morphological regularities in the lexicon. Language 51, 639671.

Jackendoff, Ray and Audring, Jenny (to appear). The texture of the lexicon. Relational Morphology and the Parallel Architecture. Oxford: Oxford University Press.

Kraak, Albert (1966). Negatieve zinnen. Een methodologische en grammatische analyse. Hilversum: W. de Haan.

Oniga, Renato (2014). Latin. A linguistic introduction. Oxford: Oxford University Press.

Schultink, Henk (1962). De morfologische valentie van het ongelede adjectief in modern Nederlands. Den Haag: Van Goor Zonen.

Schultink, Henk (1967). Transformationeel-generatieve taalbeschrijving. De Nieuwe Taalgids 60, 238257.

Spencer, Andrew M. and Zwicky, Arnold M. (1998). The handbook of morphology. Oxford: Blackwell. 